\title{
Mechanism of Embankment Reinforced with Back Berm in Road Engineering
}

\author{
Wang Qi-Hu ${ }^{*}, 1,2$ \\ ${ }^{1}$ The Key Laboratory of Urban Security and Disaster Engineering, Ministry of Education, Beijing University of \\ Technology, Beijing 100124, China \\ ${ }^{2}$ Gansu Province Transportation Planning, Survey \& Design Institute CO., LTD, Lanzhou, Gansu 730030, China
}

\begin{abstract}
Based on the nonlinear finite element method, the mechanism of embankment reinforced with back berm in road engineering reinforced has been studied. It is found there is almost no influence on the value of vertical settlement at the scope of original embankment by back berm. Only the vertical settlement under the location of back berm has been influenced lightly by back berm. The lateral displacement of embankment could be reduced or restrained by back berm. The stability of embankment enhanced when width of back berm enlarged. But the stability of embankment would not be increased any more when the width of back berm achieved its boundary value, so the width of back berm should not be bigger than the boundary value. The stability of embankment enhanced when the value of cohesion or internal friction angle of back berm increased. So rock and soil with big cohesion and internal friction angle should be used to fill back berm preferentially.
\end{abstract}

Keywords: Back berm, lateral displacement, vertical settlement.

\section{INTRODUCTION}

Stability and settlement control are the two major technical problems during embankment construction on soft foundation. In particular, the value of lateral displacement is one of the key parameters to evaluate and control the stability of soft soil embankment [1 3].

According to different engineering geological and environmental conditions, embankment could be reinforced with geotextile, anti-slide pile, foundation treatment, and so on. If the site conditions permit, embankment also could be reinforced with back berm $[4,5]$, that is, filling debris at the toe of embankment to enhance the stability of embankment, as showed in Fig. (1). Characterized with simple and convenient construction, without special construction machinery, short time for construction, locally raw material used as filling and low cost, back berm is favored by the engineer of road engineering [6 8].

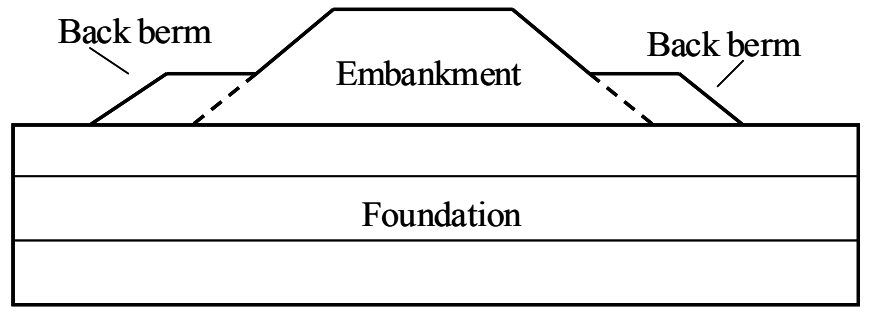

Fig. (1). Sketch map of back berm in road engineering.
Such as the section Qian-zi-dang of Jin-yi highway in China, which originally designed as a $560 \mathrm{~m}$ long large bridge, had been optimum designed as a $100 \mathrm{~m}$ long bridge and $460 \mathrm{~m}$ long embankment reinforced with back berm, which reduced project cost more than 15 million RMB [9, 10]. In the first phase of the project Hai-cang Avenue, back berm has been used by filling a large number of riprap at the toe of embankment, which reduced the lateral displacement and displacement rate, enhanced the critical embankment height $[11,12]$.

But in the corresponding codes of China, only the height of back berm has been suggested as half height of embankment, the width of back berm should be determined by calculation [13]. That is, the width of back berm is not the same with different conditions. Therefore, based on nonlinear finite element method, the effect of back berm has been systematic studied in this article, which aim to provide reference for application of back berm in engineering.

\section{CASE STUDY OF ROAD REINFORCED WITH BACK BERM}

There is a slope at Lianhuo national trunk highway (G30) Baoji to Tianshui expressway, where landslide, collapse and road blocked by slide emerged, which threaten the traffic safety of Expressway, as showed in Fig. (2).

The landslide occurred in the trailing edge of slope terrace and has been eroded strongly, at altitude of 1200 $1650 \mathrm{~m}$. The relative elevation of slope is $250 \sim 350 \mathrm{~m}$, with gradient of 25 to 45 degrees. The eluvial soil overlying slope is gravel soil, loess and silt clay, with thickness of $2 \sim 8 \mathrm{~m}$. 


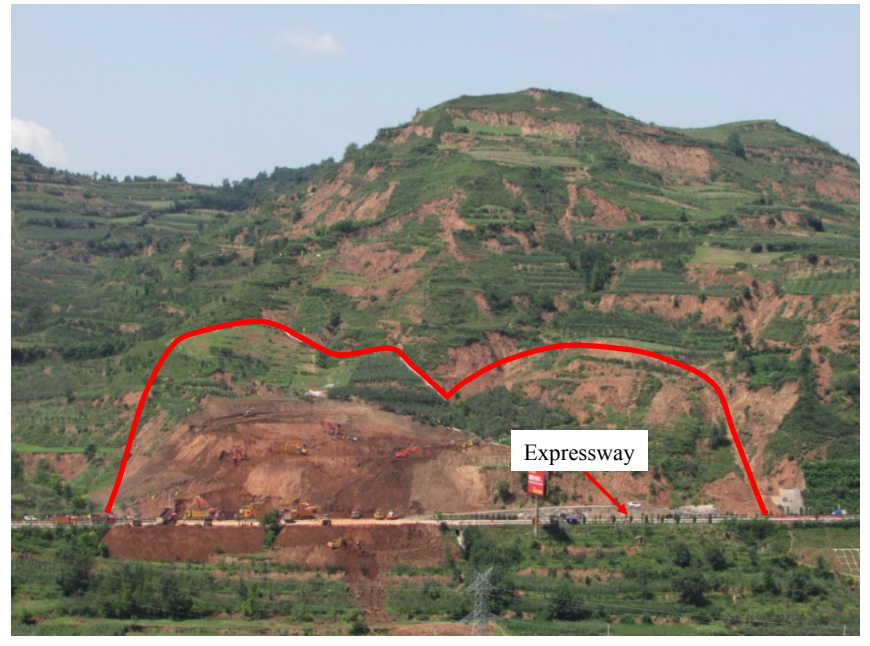

Fig. (2). Overview of the large landslide.

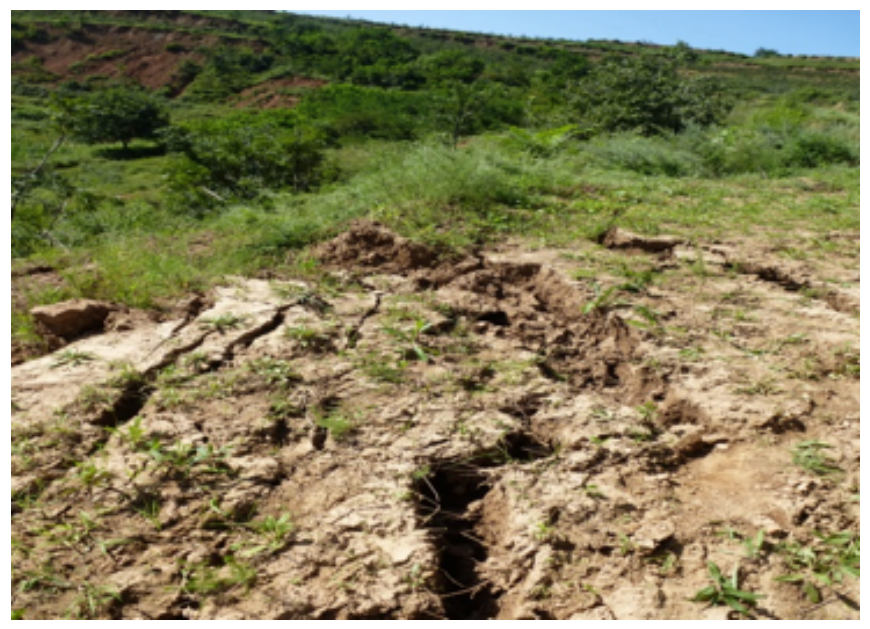

Fig. (3). Cracks at the trailing edge of landslide.

The landslide is located at a sloping terrain where north high and south low. There are three north-south gully emerged in landslide body, which transformed the slope surface morphology. Lots of cracks emerged on the surface of slope, as showed in Figs. $(\mathbf{3}, \mathbf{4})$, which indicated that big deformation happened in slope body. The original agricultural road undulated, and the maximum vertical distance of dislocation by cracks reached $6 \sim 7 \mathrm{~m}$.

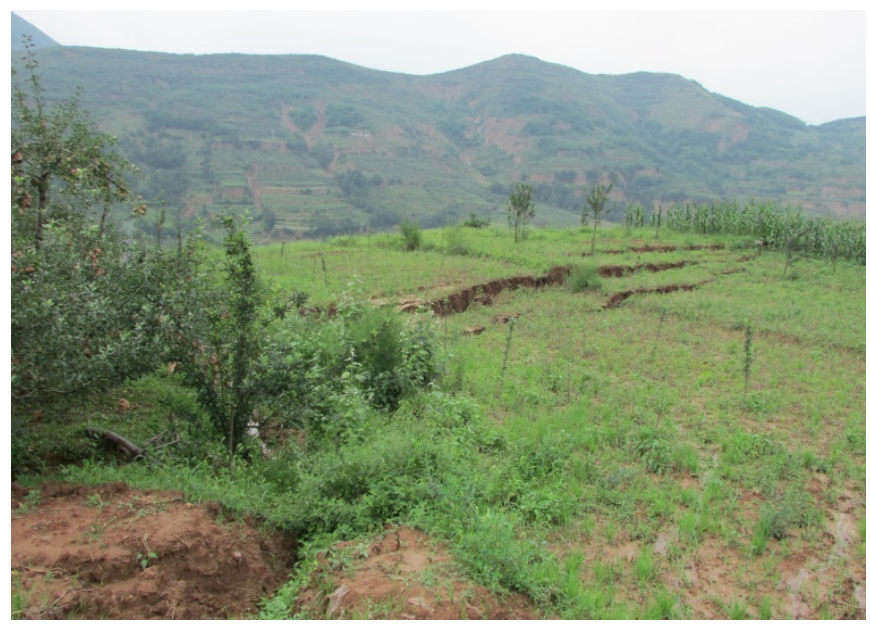

Fig. (4). Cracks at the top of landslide.
The crack or deformation of slope is mainly induced by rainfall. According to the meteorological monitoring data, the total rainfall of the year which big deformation happened in slope is about $117.9 \%$ of total rainfall of past years. On the other hand, the softening coefficient of slope layer is mostly less than 0.75 , some samples even at $0.2 \sim 0.4$. That is, the strength of slope soil would be weakened by rainfall greatly. The influence of rainfall on slope is showed in Figs. $(5,6)$.

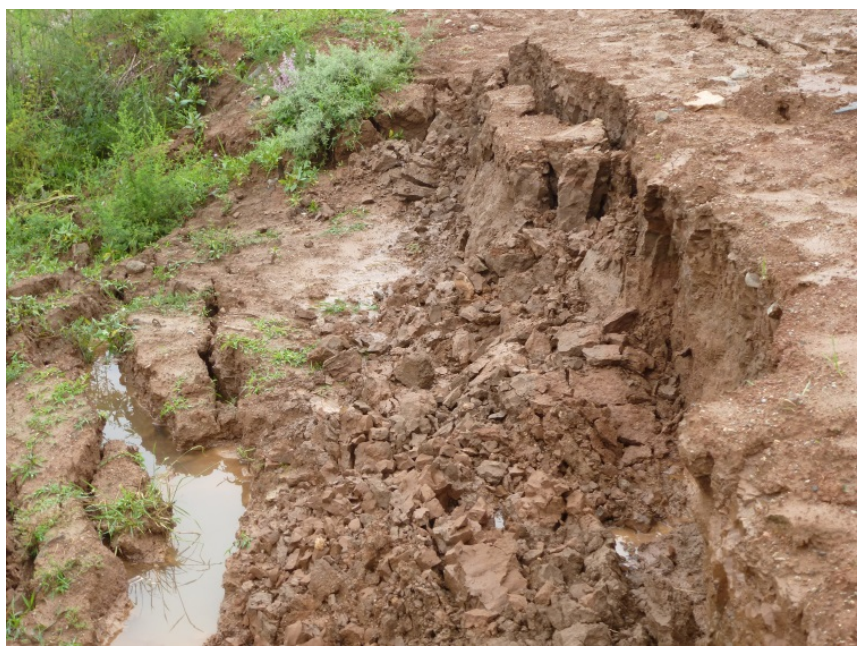

Fig. (5). Ponding water at the trailing edge of landslide.

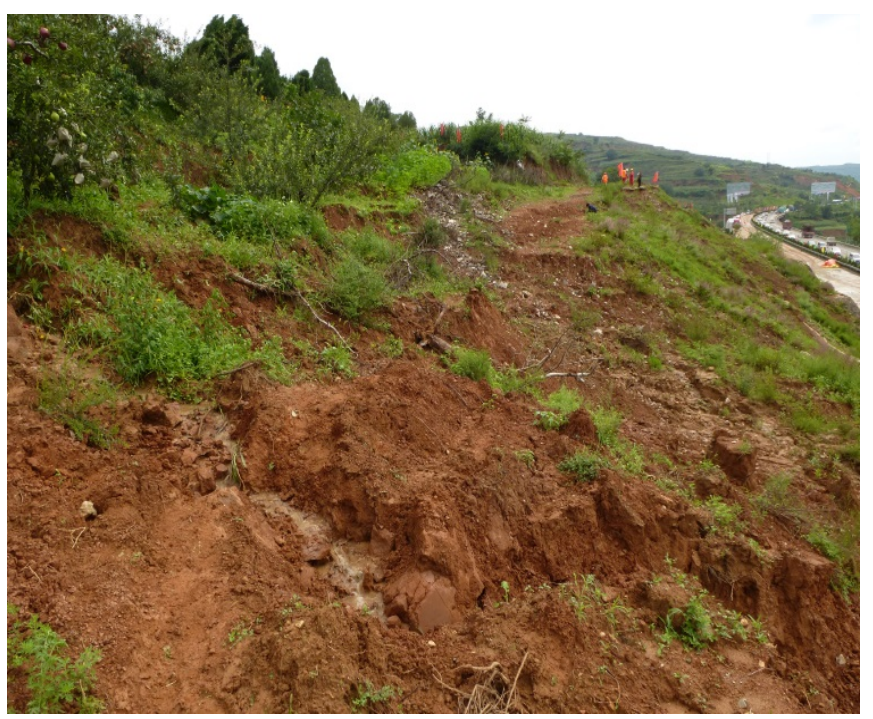

Fig. (6). Water on landslide surface.

The Baoji to Tianshui expressway passes through the front of this slope. Due to the deformation of slope, the expressway is pushed and destroyed by peristalsis of slope, as showed in Fig. (7). It can be found that the slope is very dangerous and a large-scale landslide would be happened if without reinforcement treatment. Therefore, it is necessary to use emergency measures to stop the deformation of slope to avoid disaster.

At the edge of slope, large displacement has been happened, such as some farmland has been dislocated arrive $2 \mathrm{~m}$, as showed in Fig. (8), which indicated that the limit equilibrium state of slope is coming. That is, the slope would be destroyed at any time. 
(a) view from one side

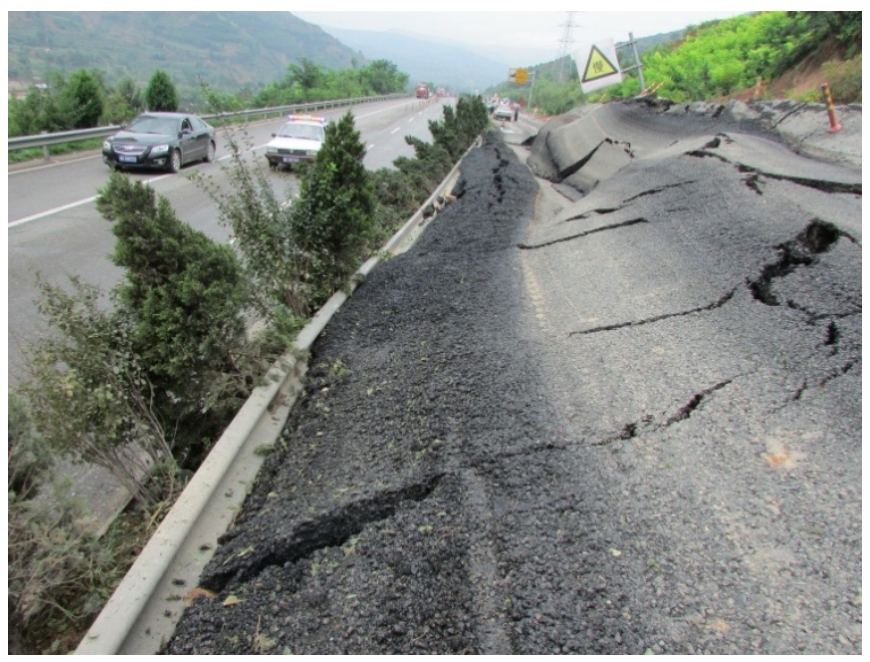

(b) view from the other side

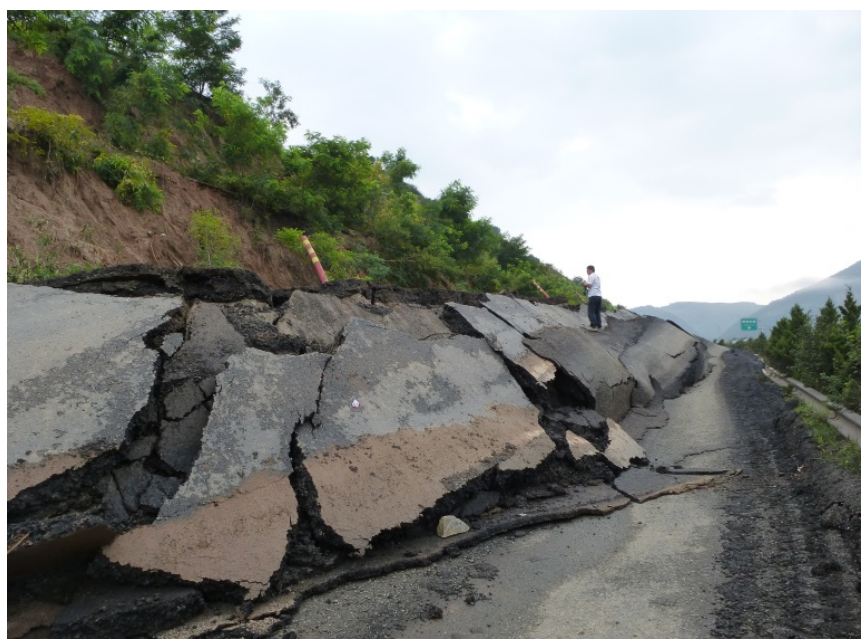

Fig. (7). Pavement bulging at the leading edge of landslide.

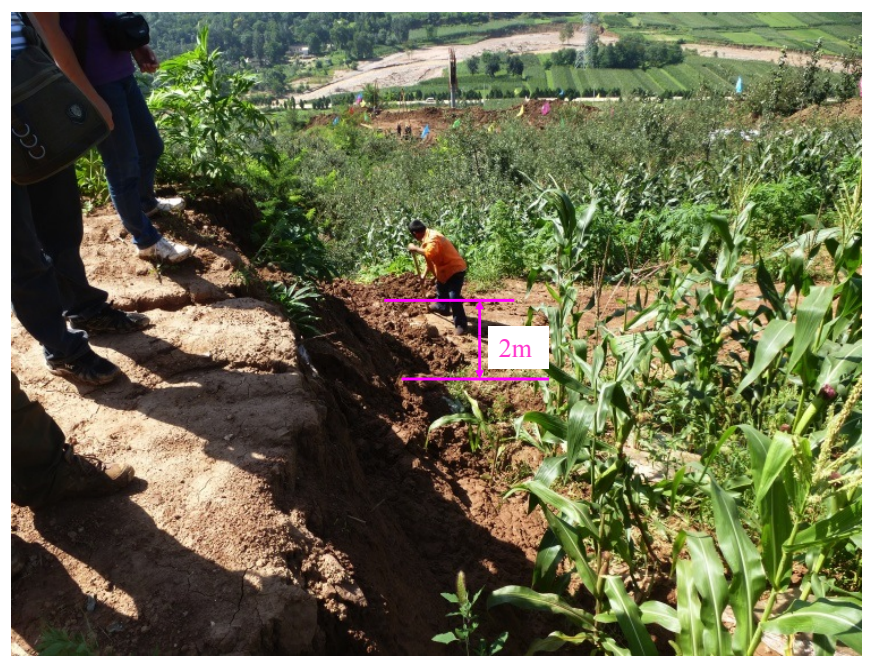

Fig. (8). Farmland dislocated $2 \mathrm{~m}$.

The landslide mainly consisted by quaternary eluvial deposit, gravel soil, silty clay, mudstone and argillaceous sandstone. According to the results of drilling, geophysical exploration and in situ tests, the slide zone is located in the underlying shale strongly weathered layer, which main ingredients containing with soft mudstone fragments and a small amount of breccia, as showed in Fig. (9).

In order to prevent the continued deformation of landslide, back berm has been used as an emergency measure in this case. That is, lots of rock and soil has been transited and filled at the toe of slope, as showed in Fig. (10). Permanent reinforcement measures, such as anti-slide pile and lattice beam, would be carried out after emergency measure ended. There is total 9 anti-slide piles with section size of $3.0 \mathrm{~m} \times 2.0 \mathrm{~m}$ has been used to reinforce the slope. Other structure and measures, such as retaining wall, drainage ditches and lattice beams would also be constructed. After permanent reinforcement measures ended, back berm would be removed according to the design of ground line.

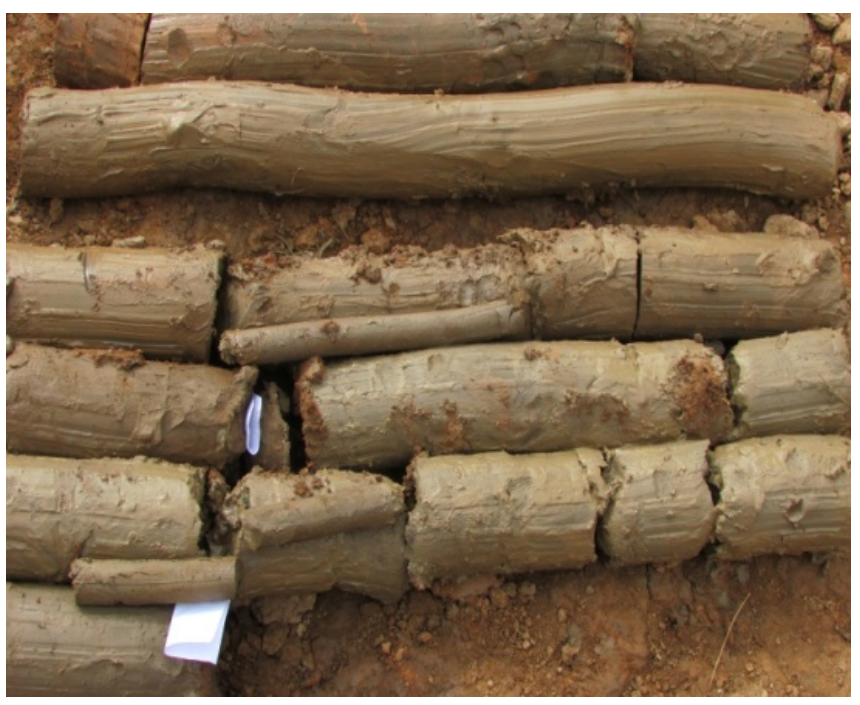

Fig. (9). Weak zone of landslide detected in drilling.

It has been verified that the slope has been rescued and reinforced by back berm, with features of fast construction speed and low cost. Therefore, it is necessary to study the effect of back berm in road engineering.

\section{THE CALCULATION MODEL OF FEM}

Now a typical section of embankment of road engineering would be analyzed, with crest width of embankment $30 \mathrm{~m}$, height of $5 \mathrm{~m}$, and slope ratio of $1: 1.5$. The model is not generated from the case mentioned above. The embankment would be reinforced by $2.5 \mathrm{~m}$ height of back berm, with the same parameters and slope ratio of embankment. Due to symmetry of embankment, a half of embankment section would be studied with FEM, as showed in Fig. (11). The foundation of embankment consisted by 3 types of clay, where clay I is the crust layer and clay II is the soft layer. The parameters of each layer are showed in Table 1.

The stress-strain relationship of foundation would be simulated with Mohr-Coulomb failure criterion. The boundary conditions of FEM are: fixed boundary condition at bottom, and horizontal direction displacement constraint condition at both sides of embankment. 


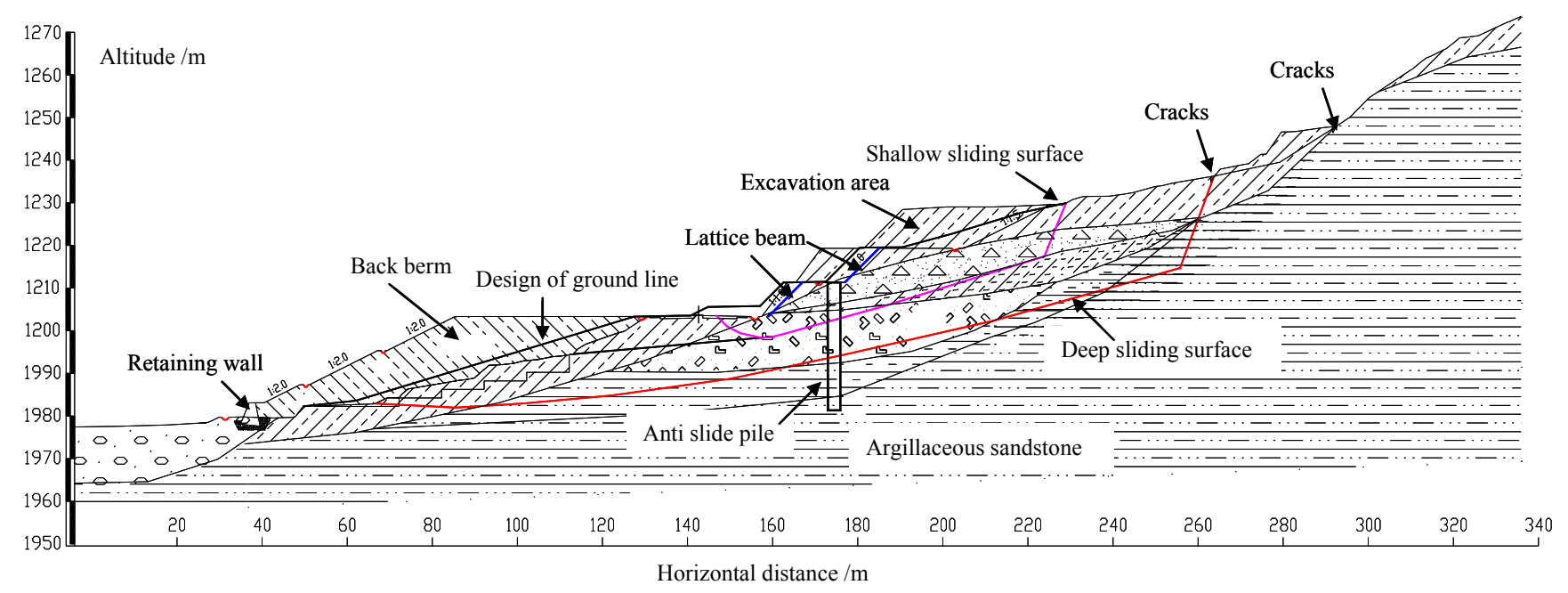

Fig. (10). Treatment design at typical section of landslide.

Table 1. Parameters of each layer.

\begin{tabular}{|c|c|c|c|c|c|}
\hline Soil Layer & Gravity/( kN.m $\left.{ }^{-3}\right)$ & Cohesive Strength/(kPa) & Internal Friction Angle $\left.\phi / \mathbf{(}^{\mathbf{0}}\right)$ & Young's Modulus $\boldsymbol{E}_{\mathbf{0}} /(\mathbf{M P a})$ & Poisson's Ratio \\
\hline \hline Embankment & 20.7 & 8.8 & 12.3 & 6.3 & 0.32 \\
\hline ClayI & 19.5 & 19.2 & 26.8 & 9.8 & 0.29 \\
\hline ClayII & 18.8 & 7.2 & 12.7 & 5.4 & 0.31 \\
\hline Clay III & 19.7 & 34.1 & 19.8 & 13.4 & 0.28 \\
\hline
\end{tabular}

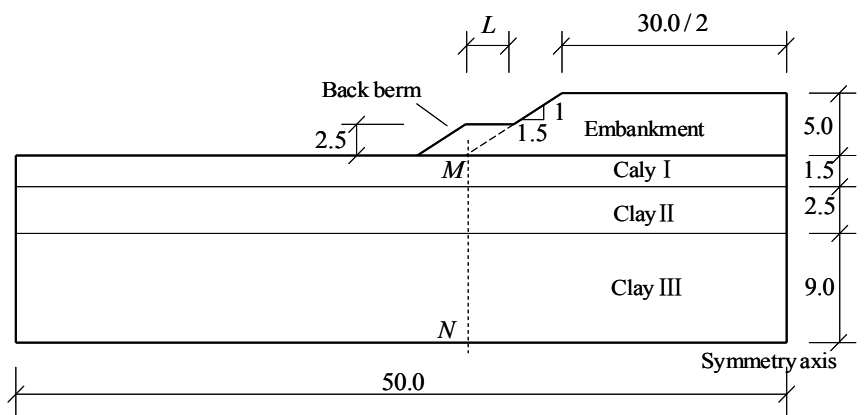

Fig. (11). Model of the embankment (unit: m).

The mesh of model with width of back berm $L=4 \mathrm{~m}$ is showed in Fig. (12), where 15 nodes triangular element have been used in grid division. According to the codes of China, back berm should be filled synchronously with embankment. The initial geostatic stress is generated by original subgrade or foundation. The construction process is simulated by activating the corresponding mesh of embankment and back berm.

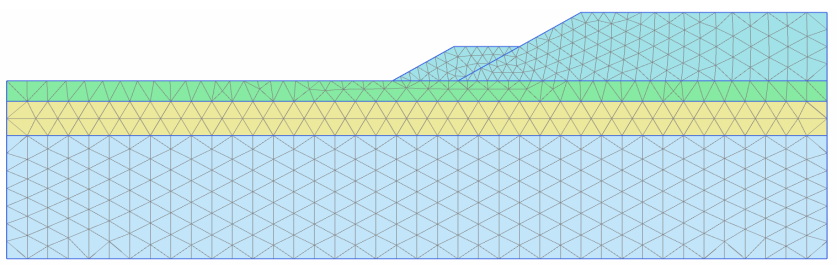

Fig. (12). Mesh of FEM with $L=4$ m (elements: 1035).

At the initial state, embankment and back berm has not been constructed, so the initial geostatic stress is only generated by foundation, as showed in Fig. (13).

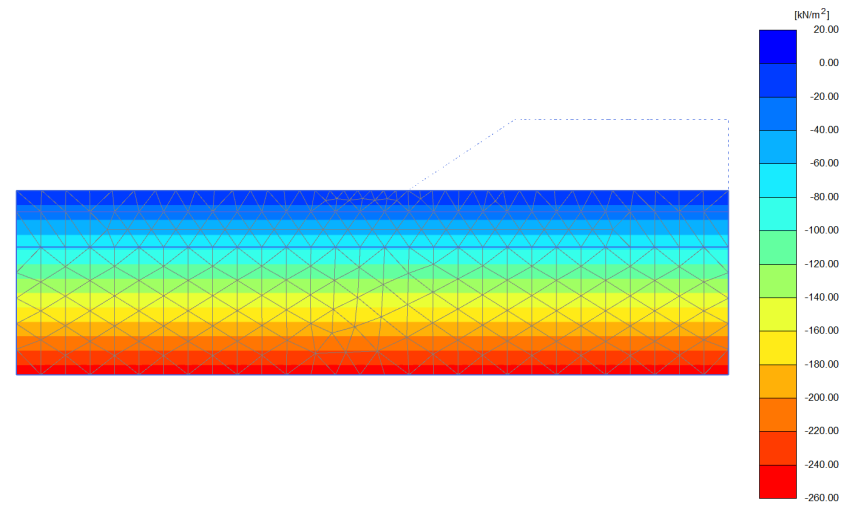

Fig. (13). Initial geostatic stress of foundation.

\section{RESULTS OF CALCULATION}

\subsection{Vertical Settlement of Embankment}

The nephogram and contour of vertical settlement are showed in Figs. $(\mathbf{1 4}, \mathbf{1 5})$. It can be found the there is almost no influence on the value of vertical settlement at the scope of original embankment by back berm. Only the vertical settlement under the location of back berm has been influenced lightly by back berm.

The value of vertical settlement at original subgrade (the top surface of clay I) is showed in Fig. (16). The maximal value of vertical settlement is $10.4 \mathrm{~cm}$, achieved at the middle of embankment. The value of vertical settlement under the location of back berm increased when width of back berm increased. There is no influence on the maximal value of vertical settlement by back berm. Due to the 
maximal value of vertical settlement is one of the controlling parameters during embankment construction, the stability of embankment during construction would not be controlled or influenced by back berm.

(a) $L=0 \mathrm{~m}$

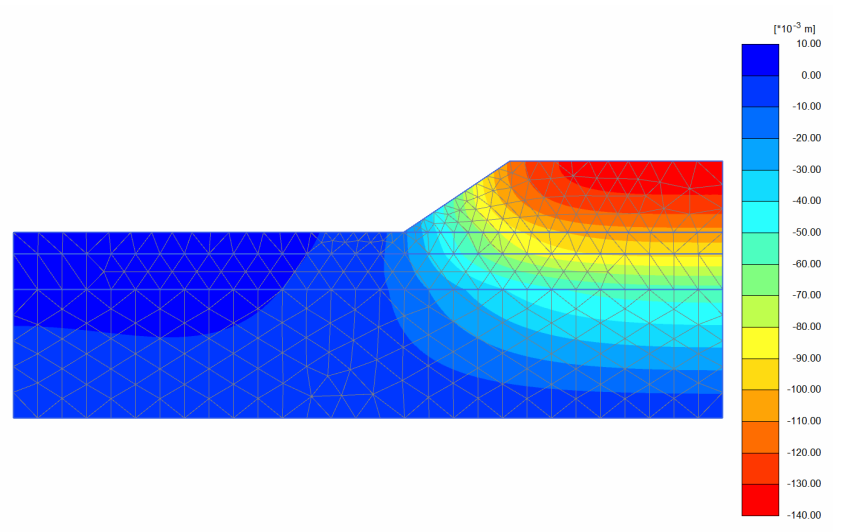

(b) $L=4 \mathrm{~m}$

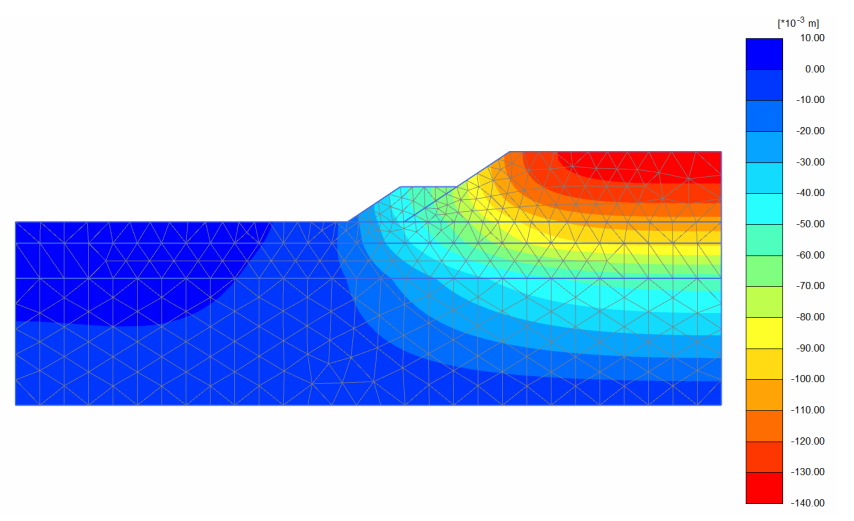

Fig. (14). Nephogram of vertical settlement of embankment.

(a) $L=1 \mathrm{~m}$

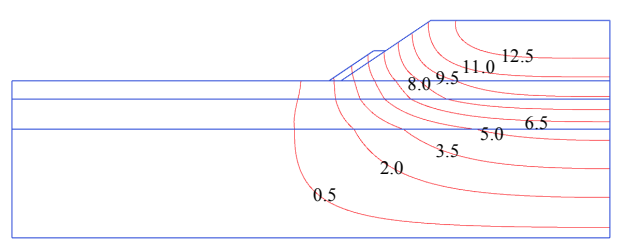

(b) $L=3 \mathrm{~m}$

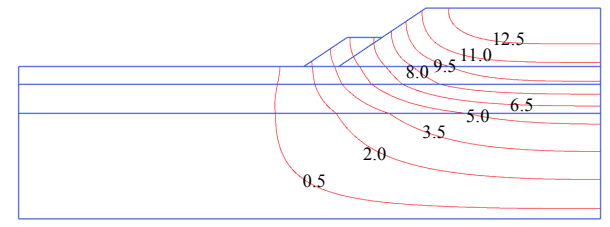

(c) $L=5 \mathrm{~m}$

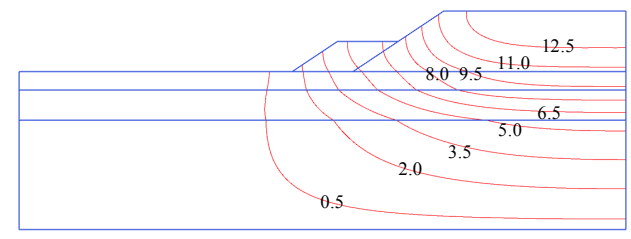

Fig. (15). Vertical settlement of embankment (unit: $\mathrm{cm}$ ).

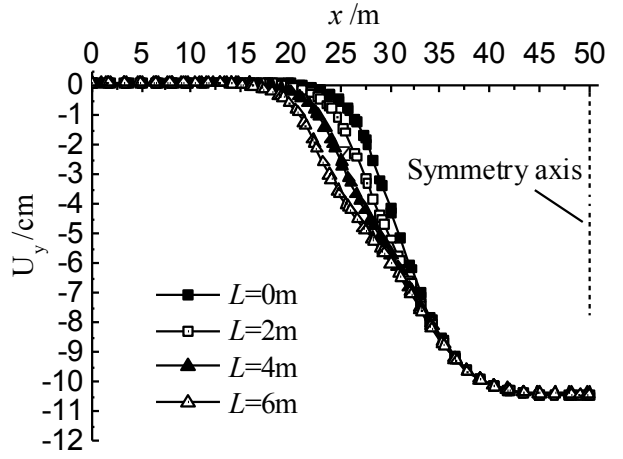

Fig. (16). Vertical settlement at original top surface of foundation.

\subsection{Lateral Displacement of Embankment}

The nephogram and contour of lateral displacement of embankment are showed in Figs. $(\mathbf{1 7}, \mathbf{1 8})$. It can be found the maximal value of lateral displacement achieved in clay II under the back berm and toe of embankment. The maximal value of lateral displacement is $2.4 \mathrm{~cm}, 2.0 \mathrm{~cm}$ and $1.9 \mathrm{~cm}$ at width of back berm $L=0 \mathrm{~m}, 4 \mathrm{~m}$ and $6 \mathrm{~m}$ respectively. Therefore, the lateral displacement of embankment is reduced or restrained by back berm.

$$
\text { (a) } L=0 \mathrm{~m}
$$

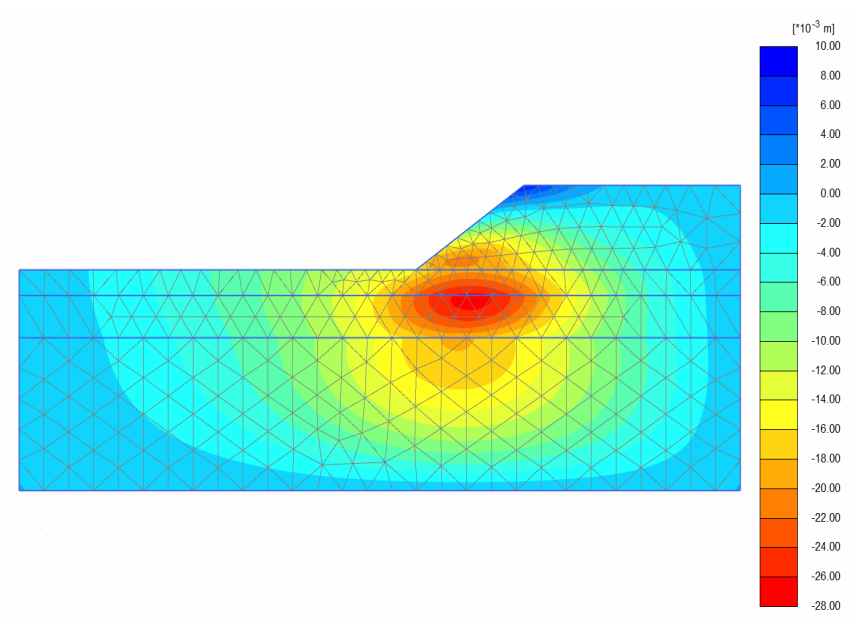

(b) $L=4 \mathrm{~m}$

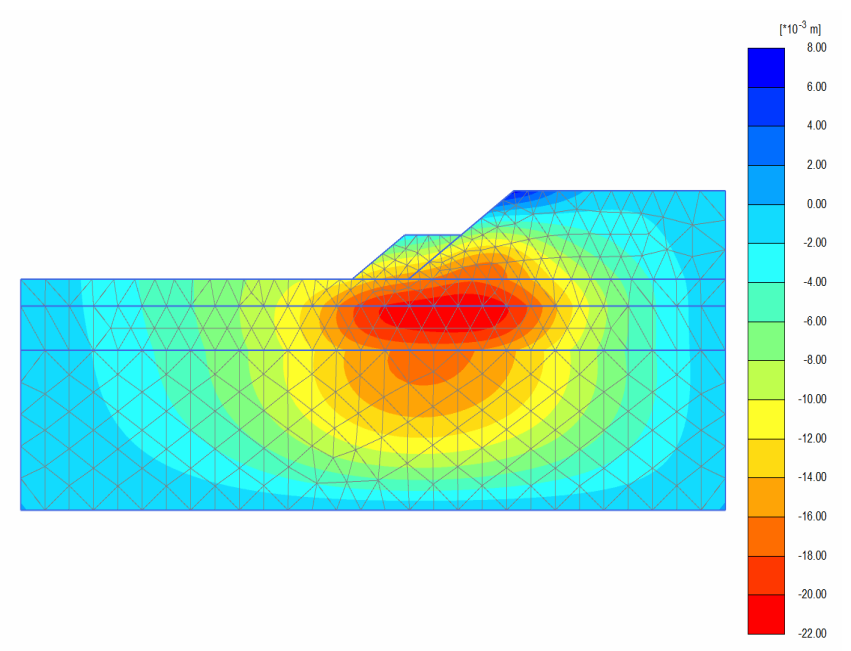

Fig. (17). Nephogram of lateral displacement of embankment. 
(a) $L=0 \mathrm{~m}$

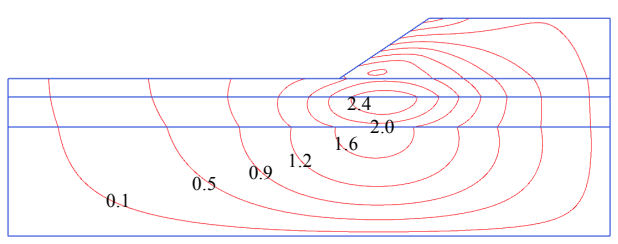

(b) $L=4 \mathrm{~m}$

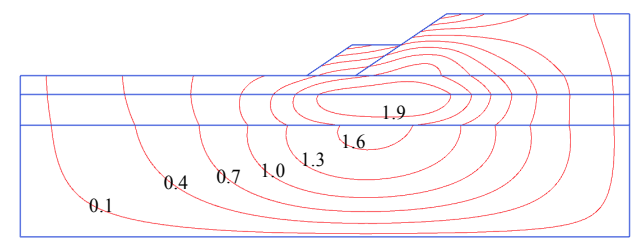

(c) $L=6 \mathrm{~m}$

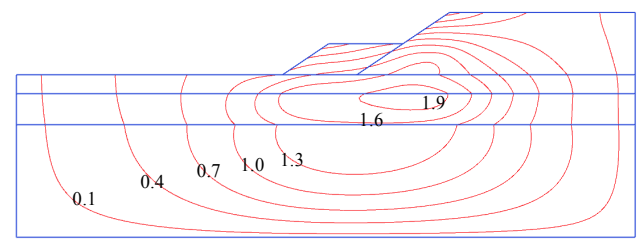

Fig. (18). Lateral displacement of embankment (unit: cm).

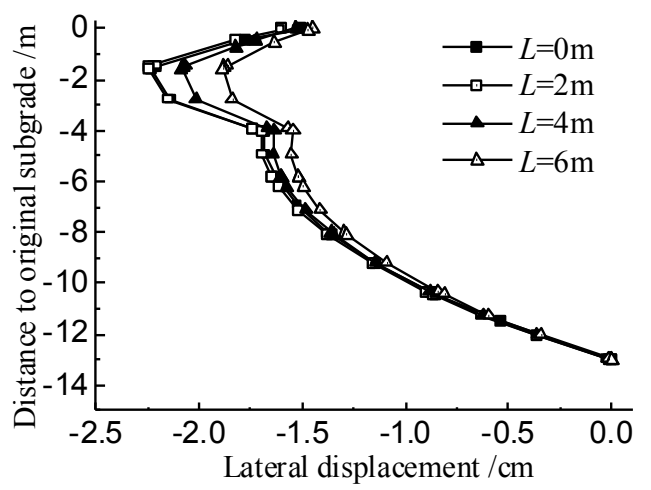

Fig. (19). Lateral displacement at vertical surface of $M N$.

The lateral displacement at vertical section $M N$ of embankment is showed in Fig. (19). It can be found that the value of lateral displacement decreased when width of back berm increased. Especially pointed out, the value of lateral displacement at $L=2 \mathrm{~m}$ is almost the same of $L=0 \mathrm{~m}$. That is, the value of lateral displacement would not be influenced by back berm when the width of back berm is too small.

\subsection{Stability of Embankment}

The relationship between stability of embankment with width of back berm is showed in Fig. (20). The safety factor of embankment is 1.10 without back berm $(L=0 \mathrm{~m})$, which smaller than the minimum requirements 1.20 , according to corresponding codes. So reinforcement should be carried out to enhance stability of original embankment.

The stability of embankment enhanced when width of back berm enlarged. But the stability of embankment would not be increased any more when the width of back berm bigger than $5.0 \mathrm{~m}$, which achieved its maximal value of
1.655. Therefore, there is a boundary value of width of back berm according to stability of embankment. The stability of embankment would not be enhanced any more, when the width of back berm bigger than the boundary value. The boundary value of width of back berm is $L_{0}=5.0 \mathrm{~m}$ in the example of this article.

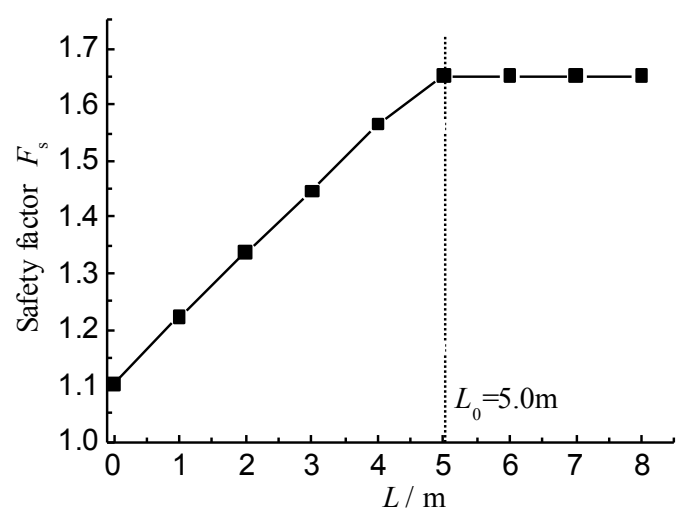

Fig. (20). Relationship between safety factor of embankment and width of back berm.

In order to make effective use of land resources and reduce width of back berm, the width of back berm should not be bigger than the boundary value. The boundary value of width of back berm could be calculated by stability of embankment according to specific engineering conditions.

The position of failure surface of embankment is showed in Fig. (21), the plastic zone of embankment is showed in Fig. (22). The failure surface is a circular arc surface through toe of embankment when the width of back berm is small. Due to the strength of clay I is very high, which act as crust layer, the failure surface could not pass through crust layer to form a bigger circular arc surface. With the increasing of width of back berm, it is very difficult to pass through the toe of embankment at failure. When the width of back berm bigger than $5 \mathrm{~m}$, the position of failure surface of embankment changer and passed through the embankment above back berm, which could be verified form the incremental displacement as showed in Fig. (23).

Particularly, there are tow potential failure surfaces in embankment at $L=4 \mathrm{~m}$, as showed in Fig. (21c), which indicated that the effect of back berm changed greatly at that conditions. Combining the safety factor of embankment as showed in Fig. (20), when reach the boundary value of width of back berm, the stability of embankment changed. That is, this change can be reflected from Fig. (21c).

\subsection{Sensitivity Analysis of Parameters of Back Berm}

The material of back berm could be obtained from raw material locally, such as stone or gravel from excavation of mountain highway engineering. Some road engineering through farmland can be combined with the farmland transformation and canal reconstruction, so the material of back berm maybe is cohesive soil or silt soil. That is, different material of back berm could be used according to different engineering conditions. Therefore, it is need to study sensitivity analysis of back berm with different parameters. 
(a) $L=0 \mathrm{~m}$

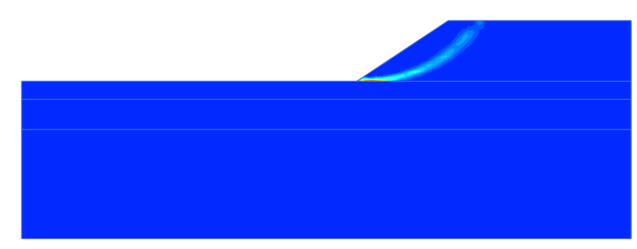

(b) $L=3 \mathrm{~m}$

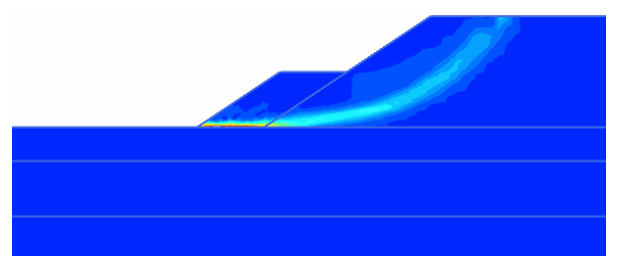

(c) $L=4 \mathrm{~m}$

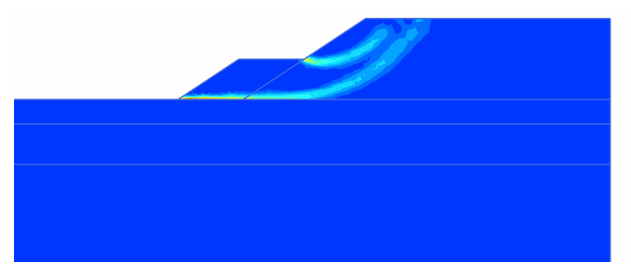

(d) $L=5 \mathrm{~m}$

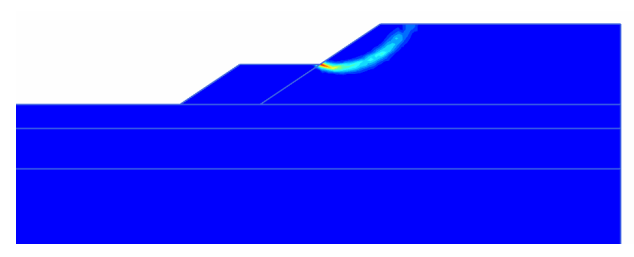

(e) $L=7 \mathrm{~m}$

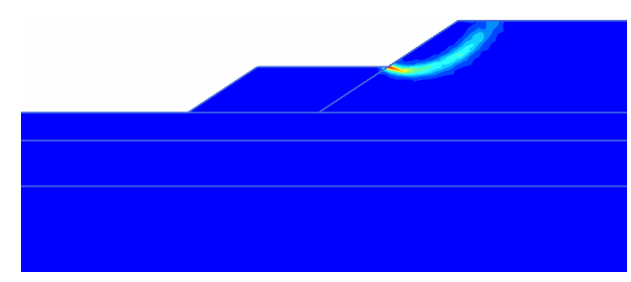

Fig. (21). Failure surface of embankment.

During sensitivity analysis, only the studied soil parameter changed and the remaining parameters unchangeable. The influence of cohesion and internal friction angle of back berm on stability of embankment is showed in Figs. $(\mathbf{2 4}, \mathbf{2 5})$, respectively. It can be found the stability of embankment enhanced when the value of cohesion or internal friction angle of back berm increased, especially at the width of back berm of $L=3.0 \sim 4.0 \mathrm{~m}$. Therefore, rock and soil with big cohesion and internal friction angle should be used to fill back berm preferentially.

Especially, when the width of back berm bigger than the boundary value $L_{0}=5.0 \mathrm{~m}$, there is no influence of different parameters of back berm on stability of embankment, for the position of fracture surface changed and through upper embankment above back berm. (a) $L=0 \mathrm{~m}$

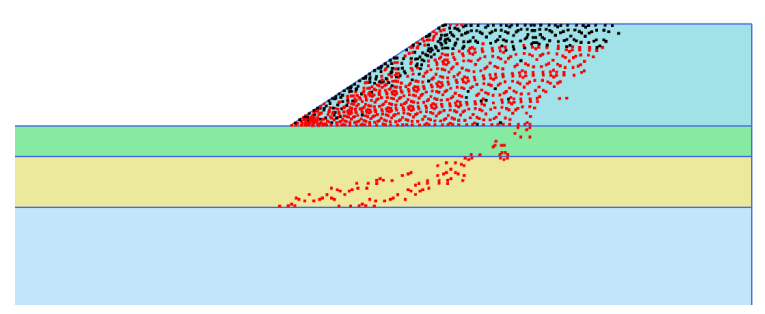

(b) $L=4 \mathrm{~m}$

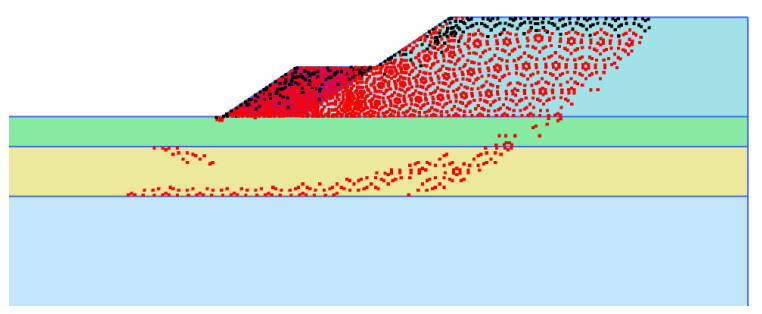

Fig. (22). Plastic zone of embankment.

(a) $L=0 \mathrm{~m}$

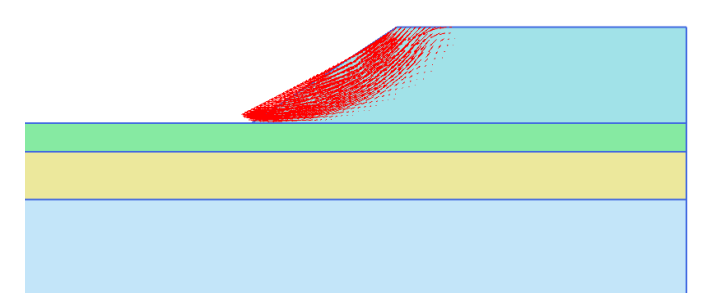

(b) $L=2 \mathrm{~m}$

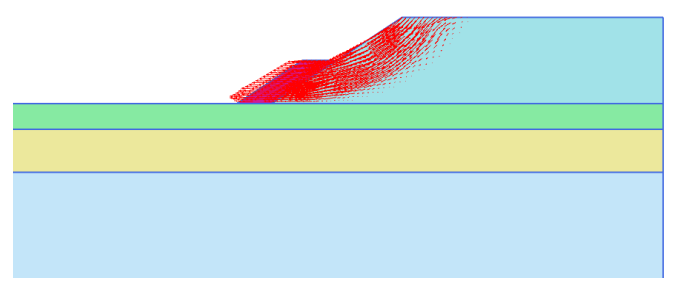

(c) $L=4 \mathrm{~m}$

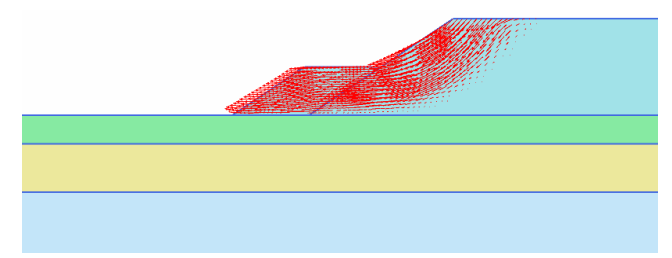

(d) $L=6 \mathrm{~m}$

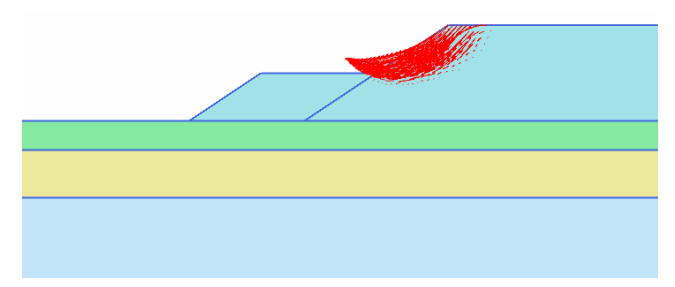

Fig. (23). Total incremental displacements of embankment. 


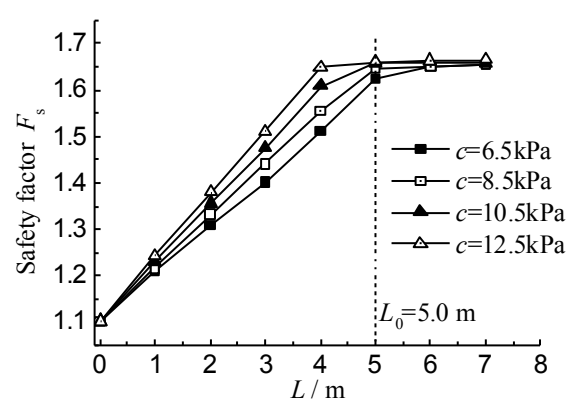

Fig. (24). Influence of cohesive strength of back berm on stability of embankment.

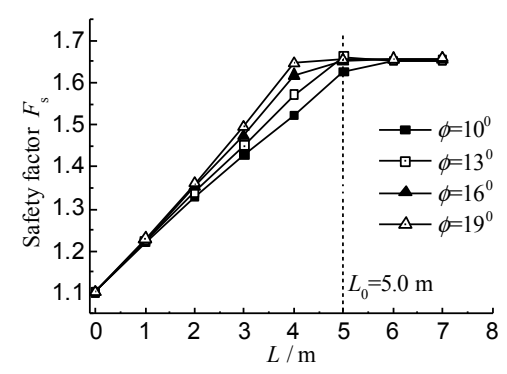

Fig. (25). Influence of internal friction angle of back berm on stability of embankment.

It is need to occupy more land by Back berm. Therefore, in order to save land and increased the land utilization rate, farming could be carried out at land of back berm, or road ancillary facilities could be installed at back berm [13].

\section{CONCLUSION}

(1) There is almost no influence on the value of vertical settlement at the scope of original embankment by back berm. Only the vertical settlement under the location of back berm has been influenced lightly by back berm. The value of vertical settlement under the location of back berm increased when width of back berm increased.

(2) The lateral displacement of embankment could be reduced or restrained by back berm. The value of lateral displacement decreased when width of back berm increased.

(3) The stability of embankment enhanced when width of back berm enlarged. But the stability of embankment would not be increased any more when the width of back berm achieved its boundary value. In order to make effective use of land resources and reduce width of back berm, the width of back berm should not be bigger than the boundary value. The boundary value of width of back berm could be calculated by stability of embankment according to specific engineering conditions.

(4) The stability of embankment enhanced when the value of cohesion or internal friction angle of back berm increased. So rock and soil with big cohesion and internal friction angle should be used to fill back berm preferentially. But there is no influence of different parameters of back berm on stability of embankment when the width of back berm bigger than the boundary value.

\section{CONFLICT OF INTEREST}

The authors confirm that this article content has no conflict of interest.

\section{ACKNOWLEDGEMENTS}

This work was financially supported by science and technology project of Gansu province communications department (No. 2011]39).

\section{REFERENCES}

[1] J. C. Chai, and N. Miura, "Traffic-load-induced permanent deformation of road on soft subsoil," Journal of Geotechnical and Geoenvironmental Engineering, vol. 128, no. 11, pp. 907-916, 2002.

[2] J. Zhou, K. Zhou, and M. Jia, "Analysis of consolidation settlement calculation for layered soft clay", Rock and Soil Mechanics, vol.31. no.3, pp 789-793, 2010. (in Chinese)

[3] S. Mei, and X. Ma, "Treatment design of the mountain side high steep fill soft soil subgrade," Journal of Engineering Geology, vol. 15, no.3, pp. 416-421, 2007. (in Chinese)

[4] J. Chen, and E. Song, "Optimized design of loading berm for high fill slope of airport in mountains area of southwest China," Engineering Mechanics, vol. 29, no.6, pp. 85-91, 2012. (in Chinese)

[5] S. Zhang, and Z. Wu, "Discussion on application of back berm in local arterial highway", Journal of Highway and Transportation Research and Development, vol. 21, no. 2, pp. 26-28, 2004. (in Chinese).

[6] A. Sakai, L. Samang, and N. Miura, "Partially-drained cyclic behavior and its application to the settlement of a low embankment road on siltyclay," Soils and Foundations, vol. 43, no.1, pp. 1006-1013, 2003.

[7] J. Liu, L. Chen, and G. J. Wang, "Contrastively studied on effect of back berm”, Yangtze River, vol.39, no. 6, pp. 77-79, 2008. (in Chinese)

[8] L. Wei, Q. He, and Y. Wang, "Comparison of settlement prediction from back analysis with forward analysis for embankment on soft soil foundation based on large strain and visco-elastoplastic model", Rock and Soil Mechanics, vol.31, no.8, pp. 2630-2636, 2010. (in Chinese)

[9] Y. Zhang, G. Yang, and H. Hu, "Stability study of embankment or dam with back berm on soft soil foundation", Rock and Soil Mechanics, vol.28, pp 844-848, 2007. (in Chinese)

[10] W. Wang, Z. Yang, and L. Yi, "Comprehensive strengthening treatment of soft surrounding rocks at shallow and unsymmetrical loading tunnel entrance", Journal of Chongqing Jiaotong University (Natural Science), vol.29, no.5, pp. 697-699, 2010. (in Chinese)

[11] K. Yan, C. Zhu, and L. Wang, "Analysis of lateral displacement in soft soil deposits under fill construction of Haicang highway", Rock and Soil Mechanics, vol. 24, pp. 465-467, 2003. (in Chinese)

[12] X. Xiang, J. Hou, and C. Zhu, "Consolidation deformation properties of silt roadbed under effect of tide," Rock and Soil Mechanics, vol.30, no. 4, pp. 1142-1146, 2009. (in Chinese)

[13] JTJ 017- 96, "Technical specification for design and construction of highway embankment on soft ground", Beijing: China Communications Press, 1997. (in Chinese) 